\title{
A (NECESSÁRIA) VIRADA PARADIGMÁTICA PARA A COMPREENSÃO DA SOCIEDADE MODERNA: OS DIREITOS HUMANOS NA ERA DA GLOBALIZAÇÃO
}

\author{
THE (NECESSARY) PARADIGMATIC TURN TO UNDERSTAND MODERN \\ SOCIETY: HUMAN RIGHTS IN THE AGE OF GLOBALIZATION
}

Leilane Serratine Grubba ${ }^{1}$

Matheus Figueiredo Nunes de Souza ${ }^{2}$

\begin{abstract}
Resumo: Existe uma insuficiência de observação das teorias sociais a fim de explicar a sociedade moderna e a sua complexidade, o que se intensificou após a queda do Muro de Berlim e com o crescimento vertiginoso das interações comunicativas em nível global. Nesse sentido, a preocupação com a questão dos direitos humanos no mundo globalizado também aumentou. Em razão disso, optou-se pelo referencial teórico de Niklas Luhmann, a fim de promover novas observações sobre as diferenças na sociedade contemporânea. Este artigo tem por objetivo a necessidade de uma virada paradigmática para a compreensão da sociedade moderna e busca analisar, por meio do método dedutivo, se esse novo olhar teórico responde à questão de compreensão e efetivação dos direitos humanos. Para cumprir com este objetivo, partiu-se de uma problematização de teorias sociológicas baseadas em pensamentos clássicos, a exemplo de Bauman e Giddens, e da insuficiência explicativa dos pensamentos tradicionais acerca dos direitos humanos e de sua busca por efetivação, para demonstrar a necessidade de uma virada paradigmática teórica no mundo globalizado. A análise será realizada a partir das teorias de Bauman e Giddens, e sua carência de observação sobre a modernidade, razão pela qual será apresentado o referencial teórico sistêmico como possível visão para o panorama social contemporâneo. Em seguida, questionam-se os pensamentos tradicionais dos direitos humanos e a busca pela efetivação, fornecendo um novo olhar reflexivo para a heterogeneidade social. Por fim, são levantadas algumas considerações acerca da falta de efetivação dos direitos humanos no âmbito internacional.
\end{abstract}

Palavras-chave: Globalização; Direitos Humanos; Teoria Sistêmica; Complexidade.

1 Doutora em Direito e Mestre em Direito pela Universidade Federal de Santa Catarina (UFSC). Mestranda Interdisciplinar em Ciências Humanas na Universidade Federal Fronteira Sul (UFFS). Estágio de Pósdoutoramento concluído na Universidade Federal de Santa Catarina. Professora Permanente do Programa de Pós-Graduação Stricto Sensu em Direito do Complexo de Ensino Superior Meridional (IMED). Professora da Escola de Direito do Complexo de Ensino Superior Meridional (IMED). Pesquisadora da Fundação Meridional. Pesquisadora Coordenadora do Projeto de Pesquisa FUNDDIH - Fundamentos e Dimensões dos Direitos Humanos (IMED/CNPq). Pesquisadora Coordenadora do Projeto de Pesquisa e Extensão CineLaw - Cinema, Direitos Humanos e Sociedade: vias para o Empoderamento (CNPq/IMED), apoiado pelo Instituto Interamericano de Derechos Humanos (IIDH) e pelo Programa Youth for Human Rights (YHRB). Membro do Corpo Diplomático e Consultora de Projetos do Programa Youth for Human Rights (YHRB). E-mail: 1sgrubba@hotmail.com

2 Bacharel (2017) e Mestre (2019) em Direito pela Faculdade Meridional (IMED), com bolsa CAPES/ PROSUP. Professor da Escola de Direito da Faculdade de Balsas (UNIBALSAS). Supervisor dos Trabalhos de Conclusão de Curso da Escola de Direito da Faculdade de Balsas (UNIBALSAS). E-mail:matheusouza@ gmail.com 


\begin{abstract}
There is an insufficient observation of social theories in order to explain modern society and its complexity, which has intensified after the fall of the Berlin Wall and with the rapid growth of communicative interactions at the global level. In this sense, concern for the issue of human rights in the globalized world has also increased. For this reason, Niklas Luhmann's theoretical framework was chosen to promote new observations about the differences in contemporary society. This article aims at a paradigm shift towards the understanding of modern society and seeks to analyze, through the deductive method, if this new theoretical view answers the question of understanding and realization of human rights. In order to fulfill this objective, we started with a problematization of sociological theories based on classical thoughts, such as Bauman and Giddens, and the explanatory insufficiency of the traditional thoughts about human rights and their search for effectiveness, to demonstrate the necessity of Theoretical paradigm shift in the globalized world. The analysis will be based on the theories of Bauman and Giddens, and their lack of observation on modernity, which is why the theoretical systemic referential will be presented as a possible vision for the contemporary social panorama. Then, the traditional human rights thinking and the search for fulfillment are questioned, providing a new reflexive look at social heterogeneity. Finally, some considerations are raised about the lack of human rights at the international level.
\end{abstract}

Keywords: Globalization; Human Rights; Systemic Theory; Complexity.

\title{
INTRODUÇÃO
}

A sociedade passa por um processo de modificação constante através do tempo, sempre se tornando cada vez mais complexa. As sociedades mais "arcaicas" tinham estruturas e formas sociais que há muito deixaram de existir, dando espaço para outras formas e estruturas que vieram com a modernidade. Sobre essa nova sociedade moderna e seus elementos, vários pensadores teorizaram.

O primeiro pensador que fez referência à "Sociologia" foi Augusto Comte, sendo considerado muitas vezes como o pai da Sociologia Moderna. Ademais, Émile Durkheim, Karl Marx e Max Weber também ocupam posição de destaque entre os clássicos da sociologia, pois sem o estudo de tais autores, afastar-se-ia de uma consciência histórica, caindo em uma armadilha de anacronismo (SELL: 2002; p. 229).

A partir dos paradigmas teóricos clássicos, como o Positivismo Sociológico (Comte), o Funcionalismo (Durkheim), o Materialismo Histórico (Marx) e a Sociologia Compreensiva (Weber), a Sociologia buscava explicar a Sociedade, em sua dimensão teórico-empírica, enquanto teoria da modernidade (SELL: 2002; p. 34-37).

Entre 1914-1918 e 1937-1945 o mundo vivenciou duas Grandes Guerras, sendo a segunda delas a mais atroz em consequências humanas. Frente a isso, decidiu-se que estava na hora de dar o devido valor ao ser humano, à igualdade de direitos e à dignidade da pessoa humana. Nesse sentido, em outubro de 1945 fundou-se a Organização das Nações Unidas, para proteger os direitos humanos de violações.

Porém, o mundo passou mais uma vez por um período de divisão, durante a Guerra Fria. Em 1991, com a queda do Muro de Berlim, a Guerra Fria terminou e a aproximação mundial cresceu vertiginosamente - dando início ao boom de integração globalizatória (VICENTE: 2009; p. 127128). E os direitos humanos tiveram que acompanhar tal crescimento.

Frente a isso, com o grau de complexidade da sociedade contemporânea e as interações sociais que ocorrem em múltiplos níveis (desde o local até o global), torna-se necessário investigar os fenômenos sociais através de outros prismas teóricos, além dos mencionados clássicos. 
Assim, partindo das explicações de Bauman e Giddens sobre a Modernidade e a Globalização, será realizada uma breve análise e se averiguara que, embora muito lúcidas as considerações, ainda faltam observações importantes. Frente a este motivo, optou-se pela Teoria dos Sistemas Autopoiéticos, de Niklas Luhmann, ${ }^{3}$ para lidar com as diferenças e a multiplicidade de contextos da Sociedade, sendo possível, também, construir novos pensamentos teóricos sobre os direitos humanos, vistos a partir do novo paradigma, como expectativa normativa de inclusão de pessoas à sociedade e aos subsistemas sociais autônomos.

Não obstante, o paradigma teórico adotado possui grande afinidade com as proposições teóricas pós-modernas de Jean-François Lyotard (1988), bem como as noções de desconstrução (do Direito) de Jacques Derrida (2010). Diante disso, o artigo visa problematizar a necessidade de uma virada paradigmática para a compreensão da sociedade moderna complexa, bem como dos direitos humanos no mundo globalizado, sendo necessário entendimento acerca da Teoria Sistêmica de Luhmann como sendo a mais adequada para responder às diferenciações funcionais da Sociedade, a fim de responder aos anseios sociais.

\section{A GLOBALIZAÇÃO E AS CONSEQUÊNCIAS DA MODERNIDADE: A SO- CIEDADE A PARTIR DE BAUMAN E GIDDENS}

Giddens (1991; p. 8-10) define a Modernidade como um estilo, um costume de vida ou organização social, que emergiu na Europa por volta do século XVII e que ulteriormente se desenvolveu para o nível mundial em sua influência. E que tanto em sua extensionalidade, quanto em sua intencionalidade, as transformações que vieram foram mais profundas do que as dos períodos precedentes.

O autor explica que a história humana é cheia de descontinuidades, e que para identificarmos essas descontinuidades que separam as instituições sociais modernas das ordens tradicionais é necessário observar algumas características envolvidas. Uma delas é o ritmo de mudança, pois a rapidez das mudanças em condições de modernidade é extrema, diferentemente do que ocorre em sistemas pré-modernos (GIDDENS: 1991; p. 12).

Outro ponto a se observar seria o escopo da mudança, pois conforme as diferentes áreas do globo são interligadas, ondas de transformações sociais penetram virtualmente a Terra. E por último, Giddens (1991; p. 12) explica que se deve verificar a natureza intrínseca das instituições modernas, pois algumas formas sociais modernas não se encontram em períodos históricos precedentes.

O sociólogo assevera que muitas coisas boas vieram com a modernidade, mas também veio, juntamente, um lado sombrio. Enquanto de um lado o desenvolvimento das instituições sociais modernas e sua difusão em escala mundial criaram oportunidades bem maiores para que os seres humanos tenham uma existência segura e gratificante, o outro lado fez com que as forças de produção

3 A Teoria proposta por Luhmann permite um diálogo interdisciplinar com a Autopoiese biológica, de Maturana e Varela; com as Leis da Forma (dos sistemas matemáticos), de George Spencer-Brown; com a Cibernética de Segunda Ordem, de Heinz Von Foerster, entre outros. 
tivessem um potencial destrutivo em larga escala, com preocupações ecológicas e o uso arbitrário do poder político (GIDDENS: 1991; p. 13-14).

Nesse sentido, deve-se completar com as considerações levantadas por Zygmunt Bauman (1999; p. 10 ss), em sua obra Globalização: as conseqüencias humanas. No primeiro capítulo da obra, Bauman explica que a globalização superou o local, e esta seria vista como privação e degradação social. Para ilustrar tal afirmação, explica que as corporações são o grande exemplo, pois ao mesmo tempo em que os investidores e donos das empresas tomam as decisões importantes, eles não estão presos à localidade, e quem acaba sofrendo as conseqüências que ficam são os funcionários.

O filósofo disserta, no segundo momento de sua obra, de que com o fenômeno da Globalização, as diferenças foram suprimidas e que a uniformização é medida de imposição - e que muitas vezes o próprio Estado busca essa padronização, citando o modelo Panóptico e alusão à 1984, de George Orwell (BAUMAN: 1999, p. 52 ss).

No capítulo de encerramento de sua obra, Bauman (1999; p. 111-114) faz crítica ao Estado e às leis, bem como disserta sobre os que sofrem as consequências e aqueles que não respondem à ela. $\mathrm{O}$ autor frisa que aqueles que sofrem com as leis, muitas vezes, são aquelas massas mais precárias da população, enquanto que a proteção é dirigida à classe média (utilizando-se do exemplo dos Estados Unidos). O número cada vez maior de indivíduos encarcerados seria produto da globalização, pois os Estados visam cada vez mais investir em segurança, ao invés de educação. Isso tudo revela as consequências humanas que a globalização traz para o mundo

Verifica-se, a partir de uma leitura rápida de ambos os autores, que o pensamento de Bauman, tomando contornos quase maniqueístas onde a Globalização traz consequências irremediáveis aos seres humanos, prejudicando a convivência - fazendo com que tudo se torne "líquido". Esse pensamento apresentado é herança do seu marxismo ortodoxo, que após o desenvolvimento de suas pesquisas, voltou-se para uma concepção humanista do marxismo.

Acerca de Giddens e sua teoria da estruturação da sociedade, busca trabalhar acerca das estruturas que formam a sociedade, relembrando que é impossível separar os sistemas sociais e as ações individuais. Trabalha no sentido não da individualidade, mas como pode existir um equilíbrio ao tratar das influências da estrutura. Vai empenhar-se, também, em tratar acerca das consequências da modernidade e procurar explicar as questões pertinentes a uma sociedade moderna.

No entanto, ambas as teorias apresentadas e brevemente explanadas não parecem conseguir dar conta de trabalhar com a complexidade social, bem como com as diferenciações funcionais emergentes a partir do processo de evolução da sociedade, pois ainda encontram-se ancoradas em demasiada ontologia, buscando uma distinção sujeito/objeto (LUHMANN: 2006; VIII). Assim, ao promover este novo marco teórico, Luhmann renuncia ao conceito de sujeito, pois este teria um conteúdo transcendental muito difícil de se evitar ao elaborar as linhas teóricas gerais. Ao fazer isso, o sociólogo alemão também afasta-se da linha basilar da sociologia que concebe a ação como base de todo fenômeno social - agora o elemento constitutivo dos sistemas sociais passa a ser a comunicação (LUHMANN: 2006; X).

Assim sendo, torna-se imperiosa a necessidade de utilização de um novo pensamento teórico apto a trabalhar com as formas, as diferenças, a complexidade e as improbabilidades geradas a partir da sociedade contemporânea. 


\section{A NECESSIDADE DE UMA NOVA TEORIA PARA A COMPREENSÃO DA SOCIEDADE MODERNA}

É preciso dizer que com o passar dos anos a Sociedade foi se modificando. O nível de interações e fluxo de informações em nível global aumentaram, principalmente após a queda do muro de Berlim, na década de 1990, marco histórico que botou fim à União das Repúblicas Socialistas Soviéticas (URSS) e à dicotomia mundial vivida durante a Guerra Fria.

O mencionado evento histórico desencadeou um processo de integração global, visivelmente percebido através dos mercados e da economia. Não obstante, com a predominância do capitalismo, o surgimento de novas tecnologias e aprimoramento de outras, a comunicação tornou-se de fato global. Ocorre que com esse processo de globalização das informações, verifica-se uma rápida reprodução comunicativa no meio social, o que também é influenciado pelas interações em níveis múltiplos (intraestatal, interestatal, supranacional e internacional).

Todos esses fatores advindos do intenso e incessante processo de globalização fazem com que a complexidade social aumente continuamente, atingindo níveis imprevisíveis de possibilidades nas mais diversas situações fáticas.

Ao observar a história da sociologia, no começo do século passado (e em particular na Alemanha, após a Segunda Grande Guerra), sua identidade foi desenvolvida escondendo suas relações com a sociedade. Visivelmente buscava teorizar sobre entidades sociais, com categorias tais como papéis, interação, intenção e ação social. Tal formação estrutural da sociologia levava a caminhos semelhantes aos das ciências naturais (BECHMANN; STEHR: 2001; p. 187).

No entanto, nos anos 80, dá-se início a um pensamento teórico inovador e complexo para sua época, proposto pelo professor de Sociologia da Universidade de Bielefeld, Niklas Luhmann. A definição do objeto de pesquisa de Luhmann, conforme sua entrevista à Universidade, antes de ser nomeado para a cadeira, seria a sociedade moderna. No momento de sua morte, em dezembro de 1998, já contava com mais de 14.000 páginas publicadas (BECHMANN; STEHR: 2001; p. 186).

Frente a isso, o jurista e sociólogo Luhmann se dedicou a estudar a fundo os sistemas sociais, a fim de transmitir a seguinte mensagem: ou a sociologia é essencialmente a teoria da sociedade, ou não é uma ciência (BECHMANN; STEHR: 2001; p. 187).

Outros modelos teóricos propõem a sociedade como um objeto dado que precede toda observação científica, onde um ponto de observação seria ocupado e estaria localizado no externo da sociedade, providenciando assim uma visão objetiva da mesma. No entanto, Luhmann faz suas proposições teóricas a fim de evitar tal armadilha, pois tanto a ciência quanto a sociedade são uma expressão da realidade social (BECHMANN; STEHR: 2001; p. 188).

O pensamento sistêmico se caracteriza pela investigação da complexidade dos fenômenos no mundo e pela instabilidade destes - é pautado pelo caráter dinâmico, transitório, de suas características. As relações que acontecem entre os sistemas e dentro deles formam uma rede de fenômenos recursivamente interligados, onde operações anteriores dão origem a operações posteriores (RODRIGUES; GRUBBA; HEINEN: 2014; p. 276-277).

No momento em que a Sociedade deixa de ser mero objeto de pesquisa e passa a ser condição de possibilidade para a própria cognição social, então a sociologia torna-se sujeito que lida consigo 
A (necessária) virada paradigmática para a compreensão da sociedade moderna: os direitos humanos...

GRUBBA, L. S.; SOUZA, M. F. N. DE.

- de forma semelhante com que a filosofia lida com a reflexão (BECHMANN; STEHR: 2001; p. 188).

Assim sendo, Luhmann transfere a estrutura de operação autorreferencial do sujeito à sua teoria dos sistemas sociais, o que provoca uma mudança radical (digna de uma viragem paradigmática) nas posições epistemológicas baseadas na dicotomia sujeito-objeto, dando uma visão anti-humanista, não ontológica e construtivista radical de sua teoria (BECHMANN; STEHR: 2001; p. 188-189).

Embora a teoria dos sistemas sociais de Luhmann importa em uma primeira visão diferenciada, cabe salientar que se apresenta como referencial teórico apto a lidar com as diferenças sociais e a complexidade do mundo moderno, com capacidade de observação de fenômenos que anteriormente não eram observados. É através de seu caráter contingencial e complexo que se busca estudar as relações para afirmação e compreensão desta mesma complexidade (RODRIGUES; GRUBBA; HEINEN: 2014; p. 282-283).

Tendo em vista que a sociedade moderna é policontextural e permite inúmeras descrições acerca de sua complexidade, a teoria da sociedade enfrenta a tarefa de elevar seu próprio potencial de complexidade: interpretar os feitos mais heterogêneos com os mesmos conceitos, e então garantir a possibilidade de comparação com os mais diversos contextos relacionados (LUHMANN: 2006; p. 26).

Bechmann e Stehr (2001; p. 189-190) explicam que o enfoque da teoria luhmanniana é que o mundo (horizonte de descrições possíveis) é expresso por uma rede de distinções e rótulos contingentes que sempre devem ser entendidos dentro de um contexto. Assim, para que um observador possa rotular "isto" como sendo "isto" (e não "aquilo") só é possível por causa da distinção feita entre os dois momentos - ou seja, algo só possui identidade própria pela sua diferença com o outro.

Como forma de lidar com a complexidade existente no mundo, surgem estruturas que realizam operações relacionadas e sucessivas, a fim de reduzir a complexidade, permitindo assim a distinção das unidades heterogêneas. Tais estruturas são denominadas sistemas, e estão divididos em quatro grandes grupos: (1) máquinas; (2) sistemas orgânicos; (3) sistemas sociais e; (4) sistemas psíquicos (LUHMANN: 1998; p. 27).

No caso das máquinas, se tratam de sistemas sem vida que não conseguem reproduzir a si mesmos. No caso dos sistemas orgânicos, as operações são processos fisiológicos. No caso dos sistemas psíquicos, as operações são os pensamentos. E no caso dos sistemas sociais, as operações são comunicações. É a partir da distinção das operações que surgem os sistemas.

Luhmann dedica-se ao estudo dos sistemas sociais, que nada mais é que a Sociedade e seus subsistemas. O sociólogo descreve a sociedade como um sistema autopoiético (que se reproduz a partir dos seus próprios elementos). Segundo sua teoria, a sociedade moderna é caracterizada pela autonomia funcional e a clausura operativa, bem como pela capacidade de se auto-organizar e de se autorreproduzir.

Os sistemas sociais são sistemas que possuem como unidade básica a comunicação. Conforme explica Leonel Severo Rocha (2013; p. 63), a sociedade é comunicação e tudo que se comunica ou faz parte da sociedade, ou é sociedade. Assim, a Sociedade é o sistema global de comunicação.

No entanto, dentro da sociedade existem os mais variados tipos de comunicação: social, jurídica, econômica, política, moral e religiosa. Para que seja possível lidar com a complexidade 
das comunicações existentes no sistema social, a Sociedade executa operações em sucessão para diferenciar cada tipo de comunicação. Essas diferenciações que surgem dentro da sociedade é que darão origem aos subsistemas, cada um com um tipo de comunicação específica (ex. Sistema Jurídico, comunicação jurídica; Sistema Político, comunicação política).

É preciso dizer que tanto o Sistema Social como seus subsistemas são diferenciados funcionalmente, bem como operam dentro de seus próprios limites e a partir de seus próprios elementos - é a ideia de autopoiése, trazida da Biologia. Humberto Maturana e Francisco Varela (1980; p. 78), preconizaram que os seres vivos seriam capazes de reproduzirem a si. No entanto, para que seja possível essa auto reprodução, é necessário que um ser vivo seja caracterizado como uma rede fechada de processos, tornando possível essa reprodução a partir de seus próprios elementos.

Porém, embora os sistemas sejam fechados operativamente, não quer dizer que sejam estáticos e fiquem incomunicáveis uns com os outros. Como o sistema é operativamente fechado, ele não pode receber elementos externos ao sistema, bem como não pode operar além das suas fronteiras. Para resolver tal situação, eles desenvolvem a chamada percepção sensorial (cognição).

Os sistemas sociais são dotados de percepção sensorial, que é o meio através do qual consegue perceber o mundo externo (entorno) e externalizar os resultados das operações (irritações) (LUHMANN: 2006; p. 89-90). A cada instante que passa, a Sociedade torna-se cada vez mais complexa e aumenta-se o número de comunicações - e os subsistemas devem evoluir para acompanhar a complexidade social (para que não sejam destruídos).

Para que o sistema evolua e acompanhe o aumento da complexidade, primeiramente ele sofre uma variação de um elemento autopoiético, respectivo aos padrões de reprodução vigentes até o momento. Então, passa à seleção da estrutura, que torna possível que a respectiva variação se constitua em condição das seguintes reproduções. Por último, ocorre a estabilização do sistema para mantê-lo dinamicamente estável para que seja possível a reprodução autopoiética da forma, que experimentou a mudança (LUHMANN: 2002; p. 304).

Nas últimas décadas muitos pressupostos tradicionais foram redefinidos frente à complexidade social, à globalização e ao pluralismo de culturas em um mesmo espaço geográfico. Exemplos dessas reformulações é o caso onde o jurista José Joaquim Gomes Canotilho (2012; p. 31) afirmou que o Dirigismo Constitucional estava morto, e que a Constituição não passava de uma "bíblia de promessas".

Diante do boom de complexidade, as matrizes epistemológicas clássicas não conseguiram lidar adequadamente com as novas observações sociais, razão pela qual a adoção de um novo modelo teórico parece ser uma medida que se impõe, a fim de que se possa compreender a sociedade moderna nas mais variadas formas que se apresenta. Por esta razão é que se apresenta o modelo pragmático-sistêmico como possibilitador de novas descrições e novas observações da sociedade moderna.

\section{OS DIREITOS HUMANOS EM UM MUNDO GLOBALIZADO}

Cabe aqui ressaltar que será analisado o papel dos direitos humanos em mundo globalizado a partir da perspectiva passada pela Organização das Nações Unidas, e se é possível se falar em efetivação completa desses direitos humanos a partir das variadas realidades verificáveis. 
Primeiro é preciso dizer que a Organização das Nações Unidas surgiu em 1945, após a Segunda Guerra Mundial. Conforme explicita Grubba (2015; p. 146), a ONU originou-se do comprometimento de cinquenta e um países para com a paz e a segurança, o desenvolvimento de relações amistosas entre as nações, a promoção do progresso social, melhores padrões de vida e direitos humanos.

É preciso salientar, no entanto, que apenas em 1948 é que adotada a Declaração Universal dos Direitos Humanos, dispondo que se deve reconhecer a dignidade inerente a todos os membros da família humana e dos seus direitos iguais e inalienáveis, que constitui fundamento da liberdade, justiça social e da paz no mundo, bem como a essencialidade de proteção aos direitos do homem através de um regime de direito (ONU, 1948).

Embora a publicação da Declaração Universal dos Direitos Humanos (DUDH) tenha ocorrido em 1948, a formalização universal apenas veio acontecer através da Conferência de Viena, em 1993, quando o fim da competição bipolar parecia propiciar uma oportunidade de fortalecimento (ALVES: 2005; p. 22).

Algumas das características dos direitos humanos, conforme cita Grubba (2015; p. 144-145), são: (1) a inerência, que significa que existem na própria natureza humana; (2) universalidade, que significa que pertence a todos os seres humanos, independente de quaisquer diferenças e; (3) indivisíveis, onde a concretização de um dos direitos depende da concretização dos demais.

Cabe dizer que, por mais que tenha sido feito um documento destinado a todos os seres humanos, o período de assinatura da Declaração era um período em que dois terços da humanidade ainda viviam sob regime colonial. Ainda, é preciso salientar que a referida Declaração foi adotada sem consenso num foro de cinquenta e seis Estados (48 aprovações e 8 abstenções), ocidentais ou “ocidentalizados" (ALVES: 2005; p. 23-24).

Conforme o artigo 17, da DUDH, a propriedade é um direito humano fundamental, seja ela para a pessoa individual ou para a coletividade. Tal disposição desagradava os países do bloco socialista. Ainda, no artigo 16 do mesmo documento, a igualdade de direitos entre homens e mulheres (principalmente no casamento), bem como a proibição de castigo cruel (artigo $5^{\circ}$ ), causavam dificuldades a países muçulmanos de legislação não secular (ALVES: 2005; p. 23-24).

Ainda que existente todas estas dificuldades e dissensos, o verdadeiro desafio, para a realidade globalizada emergente, é buscar uma forma de efetivar os direitos humanos e um desenvolvimento adequado para tais fins.

Nesse sentido, Feitosa (2009; p. 173-187) alerta que é necessário instrumentalizar uma estrutura regulatória que direcione o crescimento econômico para a efetiva promoção dos direitos humanos. Indica que o novo direito internacional está sendo direcionado para a salvaguarda de tais direitos, com mecanismos próprios de atuação e controle.

Para que haja algum grau de efetivação dos direitos humanos, é preciso que haja, também, um desenvolvimento apto a ensejar tal efetivação. A partir daí transparece que os indicadores de desenvolvimento humano estabelecidos nos últimos vinte anos integram um sistema global, podendo ser utilizados ora como indicadores de processo, ora como de resultado, no sentido de efetivação de direitos humanos, específicos ou gerais (FEITOSA; SILVA: 2012; p. 140). 
Acontece que, muito embora as vontades sejam de buscar uma concretização do discurso dos direitos humanos, nos dias de hoje a maior parte das rejeições à Declaração Universal dos Direitos Humanos parte de líderes políticos nacionais, com o objetivo de justificar violações deliberadas em ações governamentais - o que coloca muitas vezes a validade desse documento em questão (ALVES: 2005; p. 33).

A partir do momento em que se aceita o multiculturalismo como fundamento, objetivo essencial do pensamento pós-moderno, em contrapartida deve haver uma rejeição ao humanismo universalista (ALVES: 2005; p. 34).

Nesse sentido, Alves (2005; p. 35) explica que os teóricos da pós-modernidade procuram apontar saídas para as camisas de força por eles apontadas nas metas narrativas iluministas. Tentase conciliar o fim do universalismo com a luta pela identidade autônoma, a aceitação do contingente como meio para a obtenção do progresso, a substituição das Grandes Narrativas por micro discursos capazes de levar à liberdade autêntica.

É por tais motivos que se diz que a modernidade é complexa. A efetivação dos direitos humanos é posta em xeque quando acontecem violações advindas da política, ou quando não existem instrumentos eficazes de salvaguarda, ou ainda quando o discurso se mantém apenas no plano simbólico.

O panorama contemporâneo é baseado na multiculturalidade, na observação de discursos marginalizados, no reconhecimento do "outro" (alter) e na diferença. Em virtude disso, utilizar-se-á o pensamento sistêmico luhmanniano, a fim de explicar qual a real situação vivenciada pelos direitos humanos hoje.

\subsection{A FORÇA SIMBÓLICA DOS DIREITOS HUMANOS: UMA PERSPECTIVA SISTÊMICA}

A fim de fornecer uma nova visão sob a situação atual dos direitos humanos a partir de uma perspectiva de uma sociedade funcionalmente diferenciada, utilizar-se-á, como base, o artigo do professor Marcelo Neves intitulado “A Força Simbólica dos Direitos Humanos”, para fazer uma evolução sobre o tema e então poder compreender o paradoxo dos direitos humanos, enquanto formas de referência à realidade que constroem e constituem essa mesma realidade.

Embora a utilização do termo "simbólico" muito comumente remeta a uma dimensão distante do fático, é importante dizer que toda dimensão do semiótico (não apenas o simbólico) é realidade concernente à realidade (NEVES: 2005; p. 3).

Os ensinamentos de Peirce (2005; p. 46) acerca da semiótica são importantes para fazer a diferenciação do que é signo e o que é símbolo. Segundo este autor, o signo é algo que visto sob certo aspecto representa algo para alguém - ele representa alguma coisa, seu objeto.

Conforme explica, o Signo (ou Representâmen) é o "primeiro de uma relação triádica composta por um segundo, denominado seu Objeto, e um terceiro, denominado seu Interpretante". Nesta relação, o próprio signo está em relação com seu objeto (PEIRCE: 2005; p. 63).

Já o Símbolo é um Representâmen cujo caráter representativo consiste exatamente em ser uma regra que determinará seu Interpretante. Exemplos de símbolos são: palavras, frases, livros. 
A tudo aquilo que possa concretizar a ideia ligada à palavra pode-se aplicar o Símbolo (PEIRCE: 2005; p. 71-73).

É a partir dessa perspectiva de formas de referência à realidade que, de certa forma constroem essa realidade, que se forma o paradoxo dos signos, pois estes próprios signos constroem e constituem parte da realidade social, podendo ser referidos como objetos em outros planos semióticos. Assim sendo, verifica-se uma circularidade dinâmica no processo de significações, onde não se exclui “entrelaçamentos", autorreferência e circularidade (NEVES: 2005; p. 3).

Diante disso, Marcelo Neves deixa claro que a ideia de "simbólico" a ser utilizada para a compreensão da força simbólica dos direitos humanos, deve ser a seguinte: o simbólico constitui apenas uma dimensão do social e mesmo do semiótico. O simbólico importa uma linguagem ou discurso em que há um deslocamento do sentido para outra esfera de significações, conforme verifica-se na figura abaixo (NEVES: 2005; p. 3-4):

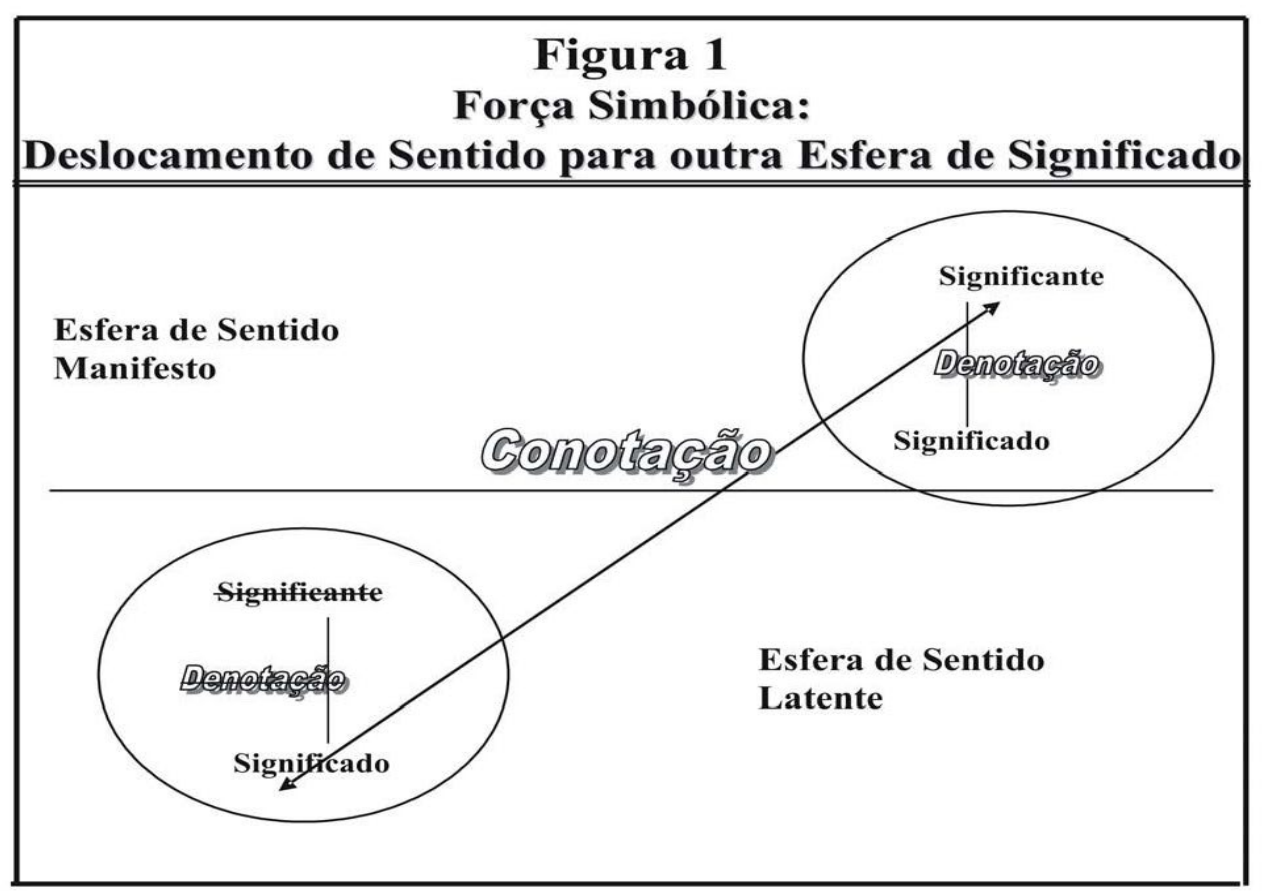

Já quando se fala da força simbólica em um âmbito normativo não quer dizer, necessariamente, que o caráter conotativo de declarações, discursos, atos e textos simbólicos vão servir à manutenção de carência dos respectivos direitos. Essa dimensão simbólica pode vir a superar situações concretas de negações de direitos (NEVES: 2005; p. 5).

É preciso dizer que, quando se fala em direitos humanos, não se aponta para a noção de direitos eternos, essenciais, a-históricos. O sentido para qual se aponta aqui é que os direitos humanos constituem uma conquista da sociedade moderna, podendo serem caracterizados, também, como uma construção ou "invenção" da modernidade (NEVES: 2005; p. 6). 
A partir de uma visão sistêmica, os direitos humanos servem como abertura da sociedade moderna para o futuro, transformando a complexidade desestruturada em complexidade estruturada ${ }^{4}$. Ou seja, os direitos humanos respondem às exigências sociais de autonomia das diversas esferas de comunicação e de discursos, mas também dizem respeito à inclusão de pessoas ou grupos (NEVES: 2005; p. 7-8).

Assim sendo, Neves (2005; p. 8) define os direitos humanos, em termos sistêmicos, como expectativas normativas de inclusão jurídica de toda e qualquer pessoa na sociedade (mundial) e, portanto, de acesso universal ao direito enquanto subsistema social (autônomo). Este conceito apresentado por Neves é esclarecedor, pois hoje, a situação de exclusão jurídica de pessoas ou grupos humanos apresenta-se como a dimensão de negação dos direitos humanos.

A afirmação do universalismo dos direitos humanos, após uma viragem paradigmática da sociedade moderna, passa a ser visto enquanto exigência de inclusão jurídica generalizada que se relaciona à heterogeneidade das pessoas e grupos no que toca a expectativas normativas, interesses e valores. Não obstante, os direitos humanos também devem afirmar-se perante às diversas ordens estatais e da ordem internacional (NEVES: 2005; p. 8).

Portanto, tendo em vista que a sociedade moderna é dotada de hipercomplexidade e de um dissenso estrutural, os direitos humanos vêm atuar na permissão de convivência em condições reais de diferença. Conforme explica Baumann (1999; p. 45), existem espaços onde reina apenas o consenso e a lógica, onde não se tolera a dissensão e a controvérsia.

Nos locais que produzem discursos baseados em consensos não há necessidade de direitos humanos - pois todos vão estar de acordo com aquilo que for debatido. O problema acontece quanto introduz o dissenso. A questão de direitos humanos se apresenta quando há a negação do outro e do discurso controverso. Exemplo claro de negação de direitos humanos enquanto inclusão jurídica são os discursos de ódio proferidos em detrimento de grupos humanos que possuem uma religião diferente da grande maioria.

Nesse mesmo sentido, Neves (2005; p. 9) explica que a inclusão jurídica universal e a autonomia discursiva constituem a moldura dentro da qual as divergências devem ser suportadas. Assim, qualquer forma de "fundamentalismo", seja religioso, étnico ou político, referente a pessoas ou grupos que pretendem uma ordem excludente de valores, ou mesmo econômico, que tende a negar a autonomia de outras esferas de comunicação e discurso, atua no sentido contrário do universalismo dos direitos humanos enquanto possibilitador da convivência social em condições de dissenso estrutural.

Para que se possa falar em direitos humanos como expectativas normativas voltadas para a inclusão jurídica em condições de dissenso estrutural, é necessário que se proceda à sua institucionalização, com a criação de procedimentos democráticos que garantam a convivência social - esses procedimentos são dotados de uma base consensual para garantir o dissenso de conteúdo.

4 Segundo Luhmann, desenvolvem-se estruturas correspondentes de assimilação da experiência, que absorvem e controlam o duplo problema da complexidade e da contingência. Acerca da contingência, essas estruturas são estabilizadoras de expectativas - elas estabilizam as expectativas sobre um comportamento e sobre as expectativas do outro. (LUHMANN: 1983; p. 45-49). 
É preciso deixar claro que a base consensual é sobre os procedimentos e não sobre o conteúdo. Exemplo disso são as eleições periódicas para alternância do poder, como forma de manutenção do caráter democrático do Estado. O consenso é sobre a promoção de eleições periódicas, mas o conteúdo, que visa a manutenção do caráter democrático, é essencialmente heterogêneo.

Ao dissertar sobre a legitimação do consenso procedimental e do dissenso conteudístico, Neves (2012; p. 137/142) assevera que as regras do jogo democrático além de determinarem o domínio da maioria também asseguram as diferenças, os pluralismos, estabelecendo participações mais abrangentes de indivíduos com o devido respeito às minorias. Na perspectiva sistêmica, a legitimação procedimental (consensual) dá ênfase a não sobreposição dos códigos de preferência do poder e da economia ao código de preferência do direito.

Ou seja, os procedimentos consensuados legítimos, a partir da perspectiva sistêmica, não podem permitir que os códigos sistêmicos da política (poder/não poder) e da economia (ter/não ter) se sobreponham ao do direito (lícito/ não lícito). Assim sendo, os direitos humanos não podem operar sob a lógica "lícito porque amigo" ou "lícito porque rico", ou, mais especificamente, só possui direito humano aquele que é amigo, ou aquele que é rico.

A legitimação procedimental garante a autonomia e a não sobreposição dos códigos, fazendo com que os direitos humanos possam, de fato, permitir a inclusão jurídica. E quando não existem tais procedimentos democráticos, ou são frágeis no âmbito internacional é que não se verifica a institucionalização plena dos direitos humanos, e por consequência, sua efetivação.

No âmbito do ordenamento jurídico internacional o processo de desenvolvimento e proteção dos direitos humanos teve início com a Carta das Nações Unidas. Em momentos posteriores, verificaram-se outros instrumentos, de caráter regional, que promoveram a proteção dos direitos, como a Convenção Europeia, a Convenção Americana e a Carta Africana.

Neves (2005; p. 23) assevera que no plano dos textos normativos no âmbito, embora haja um desenvolvimento intenso, eles ainda permanecem como uma força simbólica no Direito Internacional. A concretização e a realização das normas internacionais referentes à proteção dos direitos humanos são muito limitadas.

Alguns dos problemas identificados para a dificuldade da concretização dos direitos humanos são: a hipertrofia de sua função simbólica em detrimento da sua força normativa; a dificuldade de determinar a competência orgânica; o domínio material e a capacidade de uma proteção generalizada dos direitos humanos e; o uso político da retórica dos direitos humanos para fins de imposição dos interesses de determinadas potências (NEVES: 2005; p. 23).

Ocorre que no plano internacional acontece uma prática de relação de poder entre política e direito que guarda traços de constituições simbólicas e instrumentalistas dos Estados. De um lado, a função predominantemente simbólica é expressa, sobretudo, na Declaração Universal dos Direitos Humanos e nas garantias contidas na Carta das Nações Unidas. Do outro lado, verifica-se a falta de uma separação ("de poderes"), com a prevalência (quase absoluta) do Conselho de Segurança em relação à Corte Internacional de Justiça e à Assembleia Geral da ONU. Aquele é um órgão executivo-militar, que também desempenha funções de "natureza legislativas" e judiciais (NEVES: 2005; p. 24). 
Portanto, verifica-se que os direitos humanos no mundo globalizado, principalmente no que diz respeito à sua proteção no ordenamento jurídico internacional e sua concretização, observados a partir do modelo sistêmico, não são dotados de um essencialismo (com as mais variadas doutrinas buscando explicá-los através de fundamentos metafísicos), mas sim que são uma construção da sociedade moderna, e que se utilizam dos elementos que já fazem parte de sua estrutura para então construir-se para o futuro.

Lembrando que a Sociedade, a partir do viés sistêmico, não é constituída de pessoas, apenas de comunicação, com os direitos humanos, se constituem expectativas normativas de inclusão jurídica de toda e qualquer pessoa à Sociedade, e por consequência, de acesso ao subsistema do direito.

Assim sendo, com a complexidade do mundo moderno, os direitos humanos deixam para trás sua perspectiva essencialista (explicação utilizada para sociedades menos complexas), e passam a ser vistos, na sociedade moderna, como uma questão de inclusão/exclusão de pessoas da Sociedade. A partir disso, os direitos humanos tornam possíveis os dissensos estruturais e discursivos, possibilitando a convivência social.

Porém, para que seja possível concretizar os direitos humanos, são necessários procedimentos democráticos institucionalizados. Ocorre que quando tais procedimentos são inexistentes, ou frágeis, não se consegue uma efetivação plena dos direitos humanos.

Luhmann (2000; p. 158-159) explica que as normas são reconhecidas por meio de suas violações, e os direitos humanos na medida em que são descumpridos. A extensão das medidas das ofensas que existem em diversos Estados é assustadora. Em virtude disso, diante das atrocidades que acontecem, não se pode prender à ordem legal válida local, para saber se algo é permitido ou não. É preciso que haja comunicação de tais lesões e uma vigilância pública considerando a dimensão massificada e reprodução corrente do fenômeno.

Porém, no que diz respeito ao ordenamento jurídico internacional, as relações de poder entre política e direito acabam interferindo, em certo ponto, na efetivação, pois conforme os problemas expostos anteriormente, perguntas como (1) quem tem competência para implementar e decidir a proteção dos direitos humanos contra Estados ou organizações que os violam sistematicamente e (2) quais os casos que ensejam tal controle e sanções, ficam sem respostas.

Assim, acaba verificando-se uma hipertrofia da força simbólica dos direitos humanos em detrimento da força normativo-jurídica, principalmente no âmbito internacional. Mas é preciso dizer que, por mais que haja uma prevalência da força simbólica, constitui-se o paradoxo, pois ao mesmo tempo em que os direitos humanos estão em um plano reflexivo da realidade socialmente construída, eles também acabam construindo a própria realidade - contribuindo assim, para a construção de um caminho para a concretização.

\section{CONCLUSÃO}

Diversas teorias buscaram explicar a sociedade e o processo complexificador que acontece através da evolução social. No entanto, muitas destas visões ainda estão atreladas à pensamentos clássicos, sendo releituras de algumas proposições de Karl Marx e Max Weber. Assim, para conseguir responder aos mais variados e diferentes contextos, buscou-se auxilio na Teoria dos Sistemas 
Autopoieticos de Luhmann, pois é um pensamento que parte das diferenças e permite observações de segunda ordem dos paradoxos sociais.

Partindo desse novo paradigma teórico, também se tornou necessário repensar a questão dos direitos humanos, ainda mais em um mundo cada vez mais interligado e globalizado, deixando as explicações essencialistas e justificações metafísicas para partir para algo que faz parte da Sociedade, e ao mesmo tempo, ajuda a construir a realidade social.

Os direitos humanos enquanto atrelados às interpretações tradicionais são vistos como aqueles que nasceram juntamente com o homem e por isso não poderiam ser violados. Deus, a razão, a justiça, a natureza - todos estes já foram considerados como bases dos direitos humanos e buscavam explicar o porquê de serem inerentes aos humanos, universais e imutáveis.

No entanto, a partir de uma nova visão teórica, verifica-se que, na verdade, os direitos humanos nada mais são que uma invenção da modernidade, através da evolução social, e que sua observação deve ser feita através do paradoxo inclusão/exclusão. Através do novo olhar conceitual, a Sociedade é um espaço onde existe apenas comunicação, e os Direitos Humanos são estruturas desenvolvidas pelos sistemas sociais para estabilizar expectativas normativas de inclusão jurídica de pessoas ou grupos aos subsistemas sociais autônomos.

Ocorre que os Direitos Humanos são vistos a partir de sua Força Simbólica, que é um paradoxo - ao mesmo tempo em que faz parte da realidade social, também constitui e constrói essa mesma realidade. À medida que mais os Direitos Humanos são vistos no plano Simbólico, mais se busca implementar procedimentos democráticos para a efetivação destes direitos - sendo este o paradoxo, onde a força simbólica pode contribuir para a concretização.

Porém, quando se trata do ordenamento jurídico Internacional e as questões ligadas à Organização das Nações Unidas, encontra-se óbice, pois os discursos político e jurídico encontram uma relação de poder que influencia na falta de uma separação (“de poderes"), com a prevalência (quase absoluta) do Conselho de Segurança em relação à Corte Internacional de Justiça e à Assembleia Geral da ONU.

Assim sendo, buscou-se demonstrar a insuficiência de observação de teorias clássicas e a necessária viragem teórico-paradigmática com a adoção de um modelo capaz de lidar com a complexidade e as diferenças sociais, encontrando-se nas proposições sistêmicas de Luhmann uma outra forma de observação. Após, coube investigar a questão dos direitos humanos no mundo globalizado, percebendo-se que os discursos comuns não eram aptos a encarar a complexidade, sendo feito, assim, uma releitura dos direitos humanos a partir da teoria sistêmica e buscando explicar o paradoxo (da força simbólica) dos direitos humanos.

Por último, buscou-se destacar que no âmbito internacional das Nações Unidas ocorreu uma hipertrofia da força simbólica dos direitos humanos, bem como uma relação de poder (fora do normal) entre político e jurídico exemplificado através da supremacia do Conselho de Segurança em relação a demais órgãos, situações estas que fazem com que a força normativa dos direitos humanos diminua e torne sua concretização contingencial.

Desta forma, ao entender os direitos humanos enquanto força simbólica que faz parte da realidade social e ao mesmo tempo constrói e constitui essa realidade, verifica-se que sua efetivação pode ocorrer através do estabelecimento de procedimentos democráticos legítimos, que permitam o dissenso conteudístico e os discursos de controvérsia, tornando possível o acesso de pessoas e 
A (necessária) virada paradigmática para a compreensão da sociedade moderna: os direitos humanos...

GRUBBA, L. S.; SOUZA, M. F. N. DE.

grupos à Sociedade e aos demais subsistemas autônomos. Frente a isso, encontra-se uma resposta (provisória) que consegue lidar com a complexidade do mundo globalizado e com as diferenças, respondendo aos anseios sociais contemporâneos.

\section{REFERÊNCIAS}

ALVES, J. A. Lindgren. Os Direitos Humanos na Pós-Modernidade. São Paulo: Perspectiva, 2005.

BAUMAN, Zygmunt. Globalização: as conseqüências humanas. Rio de Janeiro: Jorge Zahar, 1999.

BECHMANN, Gotthard; STEHR, Nico. Niklas Luhmann. Tempo Social; Rev. Sociol. USP, S. Paulo, 13(2): 185-200, Novembro de 2001.

CANOTILHO, J.J. Gomes. "Brancosos" e Interconstitucionalidade: Itinerários dos Discursos sobre a Historicidade Constitucional. 2. ed. reimp. Coimbra: Editora Almedina, 2012.

FEITOSA, M. L. P. A. M. Desenvolvimento Econômico e Direitos Humanos. In: Boletim de Ciências Económicas, v. III, 2009.

FEITOSA, M. L. P. A. M.; SILVA, P. H. T. Indicadores de Desenvolvimento Humano e Efetivação de Direitos Humanos: da acumulação de riquezas à redução da pobreza. In: Revista de Direitos e Garantias Fundamentais, v. 11, 2012.

GIDDENS, Anthony. As Conseqüências da Modernidade. Trad. Raul Fiker. São Paulo: UNESP, 1991.

GRUBBA, Leilane Serratine. O Problema do Essencialismo no Direito: inerentismo e universalismo como pressupostos das teorias que sustentam o discurso das Nações Unidas sobre os direitos humanos. 2015. 283 p. Tese (Doutorado em Direito) - Centro de Ciências Jurídicas, Universidade Federal de Santa Catarina, Santa Catarina, 2015.

LUHMANN, Niklas. Sociologia do Direito I. Trad. Gustavo Bayer. Rio de Janeiro: Tempo Brasileiro, 1983.

LUHMANN. Sistemas Sociales: lineamientos para uma teoría general. Trad. Silvia Pape y Brunhilde Eker. Coord. Por Javier Torres Nafarrate. Rubí (Barcelona): Anthropos; México: Universidad Íberoamericana; Santafé de Bogotá: CEJA, Pontifícia Universidad Javeriana, 1998.

LUHMANN. O Paradoxo dos Direitos Humanos e Três Desdobramentos. Tradução: Ricardo Henrique Arruda de Paula e Paulo Antônio de Menezes Albuquerque. Themis, Fortaleza, v. 3, n. 1, p. 153-161, 2000.

LUHMANN. El Derecho de La Sociedad. Traducción: Javier Torres Nafarrate. Ciudad de México: Universidad Iberoamericana, 2002.

LUHMANN. La Sociedad de la Sociedad. Traducción: Javier Torres Nafarrate. Ciudad de México: edición Heder, 2006.

NEVES, Marcelo. A Força Simbólica dos Direitos Humanos. Revista Eletrônica de Direito do Estado, Salvador, Instituto de Direito Público da Bahia, $n^{\circ} .4$, outubro/novembro/dezembro, 2005. Disponível em: http://www.direitodoestado.com/revista/rede-4-outubro-2005-Marcelo\%20Neves.pdf. Acesso em: 27 jun. 2017.

NEVES. Entre Têmis e Leviatã: uma relação difícil: o Estado Democrático de Direito a partir e além de Luhmann e Habermas. 3. ed. São Paulo: Editora WMF Martins Fontes, 2012.

ONU. Declaração Universal dos Direitos Humanos. Organização das Nações Unidas. Paris, 1948. Disponível em: http://www.ohchr.org/EN/UDHR/Documents/UDHR_Translations/por.pdf. Acesso em: 25 jun. 2017.

PEIRCE, Charles Sanders. Semiótica. Trad. José Teixeira Coelho Neto. São Paulo: Perspectiva, 2005.

ROCHA, Leonel Severo. Introdução à teoria dos sistemas autopoiéticos do Direito. 2.ed. Porto Alegre: Livraria do Advogado, 2013. 
RODRIGUES, Horácio Wanderlei; GRUBBA, Leilane Seratine; HEINEN, Luana Renostro. Conhecer Direito II: A Epistemologia Jurídica no Brasil. Florianópolis: FUNJAB, 2014.

SELL, Carlos Eduardo. Sociologia Clássica. 4. ed. Itajaí: Editora UNIVALI, 2002.

VARELA, Francisco; MATURANA, Humberto R. Autopoiesis and Cognition: The Realization of the Living. D. Reidel Publishing Company: Dordrecht, 1980.

VICENTE, M. M. História e Comunicação na Ordem Internacional. São Paulo: Cultura Acadêmica, 2009. Disponível em: http://static.scielo.org/scielobooks/b3rzk/pdf/vicente-9788598605968.pdf. Acesso em: 30 jul. 2017.

Data de submissão do artigo: Agosto de 2017

Data de aceite do artigo: Março de 2020(*)

\section{(*) NOTA TÉCNICA:}

Esclarecemos que, em razão do ataque de hackers a que foi submetido o conjunto de periódicos da Universidade Federal de Goiás (UFG), ao que se inclui a Revista da Faculdade de Direito da UFG (RFD/UFG), os artigos ordenados entre os números 21-30, referentes ao volume 43, embora tenham sido recebidos e aceitos em datas distintas e anteriores, dado o perecimento de suas referências, foram todos registrados com o expediente de aceite no mês de março de 2020. 